\title{
Optimization And Assessment Of An Electrochemical Advanced Oxidation System For Synthetic Stormwater Treatment
}

Nathan Bettman

University of Saskatchewan

Raquibul Alam

University of Saskatchewan

Laura Patterson-Fortin

BioLargo Water Inc

Mohsen Asadi

University of Saskatchewan

Kerry McPhedran ( $\nabla$ kerry.mcphedran@usask.ca )

University of Saskatchewan https://orcid.org/0000-0001-9718-6793

\section{Research Article}

Keywords: advanced oxidation processes, electrochemical treatment, iodide, chloride, process optimization

Posted Date: February 16th, 2022

DOI: https://doi.org/10.21203/rs.3.rs-1300688/v1

License: (c) (1) This work is licensed under a Creative Commons Attribution 4.0 International License. Read Full License 


\section{Abstract}

Electrochemical Advanced Oxidation Processes (eAOPs) such as the current Advanced Oxidation System (AOS) are a type of electrochemical wastewater treatment that creates oxidative species, such as iodide species, chloride species, and hydroxyl radicals, that can treat even recalcitrant contaminants. It is important to determine the concentrations and locations of oxidative species in eAOPs for optimization of the wastewater treatment process. In this study, a spectrophotometric methodology was used to determine concentrations of iodide and chloride oxidative species (starting at 10, 25, and $50 \mathrm{ppm}$ ) within an AOS under various input voltages $(6,12$, and $24 \mathrm{~V})$. Overall, it was found that iodate and chlorite were the dominant species created in their respective treatments. Additionally, the concentration of iodide oxidative species increases with increasing voltage, whereas the chloride species decrease with increasing voltage. The optimal conditions for the efficient creation of AOS oxidative species were $12 \mathrm{~V}$ and $10 \mathrm{ppm}$ potassium iodide and $6 \mathrm{~V}$ and $10 \mathrm{ppm}$ sodium chloride, respectively. In addition, the use of iodide is recommended for wastewater treatment using the AOS to effectively create oxidative species. Following optimization, the AOS performance was tested for a synthetic stormwater. Results indicated that the AOS performed well for reduction of Eschericha coli; however, reduction of other contaminants was inconsistent as would be expected given the AOS was optimized for disinfection, not decontamination. Further AOS optimization for decontamination would lead to improved decontamination performance.

\section{Introduction}

A wide variety of anthropogenically contaminated wastewaters enter receiving waterbodies which are of ongoing concern globally due to their negative impacts on human and environmental health. Wastewaters may contain contaminants including dissolved and suspended solids, organic and inorganic matter, pathogens (including Escherichia coli), metals, pharmaceuticals, and polyaromatic hydrocarbons (PAHs), among others. Typical anthropogenic wastewaters include municipal, industrial, and agricultural wastewaters (Moreira, Boaventura, Brillas, \& Vilar, 2017; Sirés, Brillas, Oturan, Rodrigo, \& Panizza, 2014; Teh, Budiman, Shak, \& Wu, 2016); landfill leachates (Moreira et al. 2015; Oturan et al. 2015); and municipal stormwaters (Feng et al., 2018; Fraser et al., 2018; Harper \& Herr, 1987; Mohanty et al., 2014; Taylor et al., 2015). Many technologies have been developed for treatment of these wastewaters, however, there remain challenges in increasing efficiency and cost effectiveness for treatment of these wastewaters having widely varying matrices.

Conventional wastewater treatment processes can be categorized into physical, chemical, and biological processes. Examples of physical treatment methods include bar racks/screens, sedimentation, and filtration (Clark \& Pitt, 2012; Mickova, 2015). Common chemical treatment processes include coagulation/flocculation (Clark \& Pitt, 2012; Harper \& Herr, 1987; Sansalone \& Kim, 2008; Teh et al., 2016), air stripping towers, activated carbon adsorption, and ion exchange processes (Ding et al., 2017; Ganiyu, Vieira dos Santos, Tossi de Araújo Costa, \& Martínez-Huitle, 2018; Moreira, Soler, et al., 2015). In addition, chemical treatments are often used for disinfection with chlorine, ozone, and UV typically used based on 
their ability to economically kill a variety of pathogens (Clark \& Pitt, 2012; Hussain, De las Heras, Asghar, Brown, \& Roberts, 2014; Mickova, 2015). Examples of biological treatments include fixed growth, suspended solids growth, trickling filters, activated sludge, rotating biological contactor, facultative ponds, and aerated lagoons (Clark \& Pitt, 2012; Fraser et al., 2018; Mickova, 2015; Mohanty et al., 2014; Moreira, Boaventura, Brillas, \& Vilar, 2015). In general, these conventional processes are reasonably effective when used individually, or in treatment process trains; however, these may not be as effective in treating more complex and recalcitrant wastewater contaminants (Chauhan, Dinesh, Alawa, \& Chakma, 2021). For example, biological treatment processes transform complex pollutants into some intermediates with the potential of accumulating in the environment (Bilińska, Gmurek, \& Ledakowicz, 2016). There then is a need to advanced wastewater treatment processes to complete the pollutant removal processes (Ahmadi, Ramavandi, \& Sahebi, 2015).

Of more recent interest are advanced wastewater treatment processes, such as electrochemical advanced oxidation process (eAOP) technologies which rely upon oxidative electrochemical species for wastewater treatment (Bergmann et al., 2014; Feng et al., 2016; Ganiyu et al., 2018; Moreira et al., 2015; Deng et al., 2019; Vidal et al., 2019; Srinivasan and Nambi, 2020). Generally, eAOPs have been used as a pretreatment to increase efficiencies of downstream processes or as a post-treatment polishing step to meet effluent standards (Chan et al., 2012; Moreira et al., 2015; Oturan et al., 2015). Advantages of eAOPs include versatility, high efficiency, low resource consumption, and potential cost-effectiveness (Ding et al., 2017; Mickova, 2015; Radjenovic \& Sedlak, 2015; Sirés et al., 2014). However, high electrode costs, low conductance of some wastewaters (e.g., stormwater) and potential for release of toxic by-products can be challenges for eAOP technologies (Bergmann et al., 2014; Mickova, 2015; Radjenovic \& Sedlak, 2015) which highlight the need for further optimization of both electric supply and operational conditions to improve treatment efficiencies, reduce energy consumption, and, in turn, be more cost-effective (Seibert et al., 2020).

A potentially low cost method to increase effectiveness is the addition of salts, such as iodide and chloride, that reduce a treatment reactor's potential and increase the oxidation process efficiency (Cañizares et al., 2006; Llanos, Cotillas, Cañizares, \& Rodrigo, 2014). This is especially the case for stormwater which can have relatively low electrical conductivity (herein fluctuating between $331-2,080$ $\mu \mathrm{s} / \mathrm{cm}$ ). Similarly, previous studies have reported that the addition of salts can lead to electrogenerated strong oxidant formation during electrochemical oxidation resulting in higher pollutant (such as organic carbons, phenolic-based compounds, and pharmaceuticals) removal rates from hospital/industrial wastewater (Fajardo et al., 2017; Lan, Coetsier, Causserand, \& Serrano, 2017). Although salt addition may be beneficial for improved electrochemical treatment, it may not be sufficiently effective for all pollutants. For example, sulphate addition has been reported has limited effectiveness for the removal of salbutamol (Lan et al., 2017). Therefore, there is a need to investigate the interaction of salt and pollutants in order to determine optimal salt types and concentrations. Additionally, the reactor conditions need to be optimized for various salt concentrations and salt types to create the most effective oxidants at low voltages for cost efficiency. 
Currently, our research group has been assessing a novel iodide-based eAOP known as the AOS (Advanced Oxidation System: Figure 1; BioLargo Water Inc., Canada; Moustafa et al., 2021) for the treatment of municipal and synthetic stormwaters given its exceptional performance in other water treatment applications (Moustafa et al., 2021). To our knowledge, this is the first application of iodidebased eAOP used for stormwater treatment. The determination of oxidative species created while treating real wastewaters is not realistic given their complex matrices and the short-lived nature of the created oxidative species within eAOP reactors. Thus, the first objective of the current study was to assess the AOS potential for the treatment of wastewaters through the determination of concentrations of produced oxidative iodide and chloride species within the reactor to better understand iodide-based eAOP versus a more typical chloride-based eAOP. Therefore, three concentrations (10,25, and $50 \mathrm{ppm}$ ) each of potassium iodide $(\mathrm{KI})$ or sodium chloride $(\mathrm{NaCl})$ prepared in distilled water (DI) were added to the influent AOS water and three voltage levels $(6,12$, and $24 \mathrm{~V})$ were applied to the AOS. The KI has been recognised to create strong oxidative species such as iodate $\left(\mathrm{IO}_{3}{ }^{-}\right)$and periodate $\left(\mathrm{IO}_{4}{ }^{-}\right)$(Moustafa et al. 2021); while $\mathrm{NaCl}$ was chosen given chloride is frequently found in typical wastewaters and creates oxidative species including hypochlorite $\left(\mathrm{ClO}^{-}\right)$, chlorite $\left(\mathrm{ClO}_{2}{ }^{-}\right)$, and chlorate $\left(\mathrm{ClO}_{3}{ }^{-}\right)$.

In addition to DI water, tap water was considered in some experiments given it contains chloride in a simpler matrix than wastewaters, thus, oxidative species formed could be readily determined. Given the short-lived nature of the oxidative species, sampling and analysis via typical instrumentation would not be feasible. Thus, a novel methodology of determination of both iodide and chloride species was used such that the species could be determined quickly via UV-vis spectrometry given its simplicity, accuracy, quick response and accessibility (Afkhami, Madrakian, \& Zarei, 2001), specifically as compared to ion chromatography. The second objective was the assessment of a synthetic stormwater matrix including $E$. coli and a variety of other known stormwater contaminants to determine the potential for AOS to be used for treatment of real stormwaters. Results determined from the overall AOS assessment and optimization, in addition to the synthetic stormwater treatment, may be useful in informing the treatment of real stormwaters, and other wastewater matrices, using this eAOP technology.

\section{Methods}

\subsection{The Advanced Oxidation System (AOS)}

The laboratory-scale AOS was made of a cylindrical reactor whose schematic is shown in Figure 1 as provided by BioLargo Water Inc., Canada. A detailed description of the AOS can be found in Moustafa et al. (2021) with a brief overview included herein. The reactor has a 1-inch diameter with a series of alternating proprietary materials used as anodes and cathodes made up of expanded graphite given its high stability, developed specific surface, electrical conductivity, and temperature resistance (Li, Feng, \& Jia, 2006; Li, Liu, \& Da, 2007). The anodes and cathodes were subjected to voltages applied via a DC power supply while separated by glass wool to have increased production of oxidative species. The reactor was operated in an upflow configuration using a peristaltic pump set at a constant $5 \mathrm{~mL} / \mathrm{min}$ flow 
rate resulting in a residence time of about 30 minutes for all experiments. Sampling ports were located throughout the reactor with five anode ports (A1-A5) and three cathode ports (C1-C2, C3=0utlet). The expectation was that oxidative species would be generated at the anodes and depleted at the cathodes, and the system cathodic cells would, thus, result in the minimization of the potential for release of active chemical discharges into the environment (Moustafa et al., 2021). Thus, the sampling ports were staggered to sample from each of these reactor volumes.

Before each experiment, the reactor was 'recharged' to remove residual contaminants that could be in the reactor and to ensure the ability of the reactor to create oxidative species before samples were collected. Firstly, the reactor was flushed with distilled (DI) water for $30 \mathrm{~min}$. Then, the voltage was turned on and the AOS run with either the iodide or chloride influent water for $30 \mathrm{~min}$ (treatment dependent). Samples were then taken from each port prior to analysis via UV-vis as discussed in the following section. To facilitate the reaction(s) used to measure the oxidative species, $1 \mathrm{~mL}$ each of the sample and $0.64 \mathrm{M} \mathrm{KI}, 2$ $\mathrm{mL}$ of the buffer and $6 \mathrm{~mL}$ of water was mixed in a $10 \mathrm{~mL}$ flask. The mixture was then transferred to a glass cell to be read by the spectrophotometer. It is important to note that the anode $\mathrm{pH}$ values typically decrease as cathode $\mathrm{pH}$ values increase making the reactor $\mathrm{pH}$ a dynamic environment (Jadhav \& Ghangrekar, 2009). Therefore, several different buffers were used to adjust the $\mathrm{pH}$ of the samples in order to determine the individual oxidative species given the need for associated reactions to each oxidative species at a certain pH to create peaks as shown in the Supporting Information (Sl; Table S1). All experimental conditions included for assessment of the AOS are summarized in Table 1. 
Table 1

Experimental conditions of various iodide $(\mathrm{KI})$ and chloride $(\mathrm{NaCl})$ concentrations and voltages. The 'No salt' treatment includes only tap water at various voltages.

\begin{tabular}{|c|c|c|}
\hline Treatment & Concentration (ppm) & $\begin{array}{l}\text { Voltage } \\
\text { (V) }\end{array}$ \\
\hline \multirow[t]{11}{*}{ KI } & 10 & 6 \\
\hline & 10 & 12 \\
\hline & 10 & 24 \\
\hline & 25 & 6 \\
\hline & 25 & 12 \\
\hline & 25 & 24 \\
\hline & 50 & 6 \\
\hline & 50 & 12 \\
\hline & $50+$ Tap & 6 \\
\hline & $50+$ Tap & 12 \\
\hline & $50+$ Tap & 24 \\
\hline \multirow[t]{9}{*}{$\mathrm{NaCl}$} & 10 & 6 \\
\hline & 10 & 12 \\
\hline & 10 & 24 \\
\hline & 25 & 6 \\
\hline & 25 & 12 \\
\hline & 25 & 24 \\
\hline & 50 & 6 \\
\hline & 50 & 12 \\
\hline & 50 & 24 \\
\hline \multirow[t]{3}{*}{ No salt } & Tap & 6 \\
\hline & Tap & 12 \\
\hline & Tap & 24 \\
\hline
\end{tabular}


The potassium iodide $(\mathrm{KI})$ and sodium chloride $(\mathrm{NaCl})$ were purchased from Fisher Scientific (Thermo Fisher Scientific, MA, USA) and were of ACS grade purity. The distilled water was produced via a Millipore Direct-Q 8 UV system with a conductivity of $18.2 \mathrm{M} \Omega / \mathrm{cm}$ (Millipore Canada, ON, CA). The 10, 25, and 50 ppm solutions for each salt were produced fresh for each experimental run. A HACH DR 4000 UV-vis spectrophotometer (Hach Canada, ON, CA) with a 1-cm glass cell was used to determine the concentrations of the oxidative species. The periodate, and iodate detection limits and ranges were 0.05 $-8.00 \mu \mathrm{g} / \mathrm{mL}$, and $0.05-5.00 \mu \mathrm{g} / \mathrm{mL}$, respectively. Calibration curves for each oxidative species at their corresponding absorbances were developed prior to experimental runs as discussed in the following sections. After recharging, the AOS was operated at the various concentrations and at 6,12 , and $24 \mathrm{~V}$. Samples were taken from each sampling port while the reactor was in operation, $\mathrm{pH}$ adjusted in a $10 \mathrm{~mL}$ flask, and $\sim 1 \mathrm{~mL}$ was placed into the glass cell which was then immediately tested for absorbance. These experiments were conducted in the Environmental Engineering laboratories at the University of Saskatchewan.

\subsection{1 lodide species in AOS}

The iodide species considered were iodate $\left(\mathrm{IO}_{3}{ }^{-}\right)$and periodate $\left(\mathrm{IO}_{4}{ }^{-}\right)$as they are predicted to be created by electrochemical oxidation. Prior to the current experiments, these have been shown to be the dominant species in the AOS based on parallel research done by our group at the HXMA beamline of the Canadian Light Source (CLS, SK, CA) as shown in Supporting Figure S1. Currently, the iodide species were determined using a method described by Afkhami et al. (2001) based on their reaction with excess iodide to create triiodide $\left(\mathrm{I}_{3}{ }^{-}\right)$as follows (Eq. 1 and 2):

$$
\mathrm{IO}_{4}^{-}+11 \mathrm{I}^{-}+8 \mathrm{H}^{+} \leftrightarrow 4 \mathrm{I}_{3}^{-}+4 \mathrm{H}_{2} \mathrm{O}
$$

1

$$
\mathrm{IO}_{3}^{-}+8 \mathrm{I}^{-}+6 \mathrm{H}^{+} \leftrightarrow 3 \mathrm{I}_{3}^{-}+3 \mathrm{H}_{2} \mathrm{O}
$$

The concentration of the species was determined spectrophotometrically by measuring the absorbance of the triiodide at $352 \mathrm{~nm}$ (Afkhami et al., 2001; Feng et al. 2017; Wang et al. 2018). The reactions are pH dependent with periodate reacting at $\mathrm{pH} 6$ and both species reacting at $\mathrm{pH}$ 3.3. These reactions will result in the creation of two equations for the absorbance values (Eq. 3 and 4); therefore, the concentration of each individual species can then be determined when both species are in a mixture by solving these equations simultaneously.

$A_{1}=a_{1}+b_{1} C_{\text {periodate }}(3)$

$A_{2}=a_{2}+b_{2} C_{\text {periodate }}+b_{2}^{\prime} C_{\text {iodate }}(4)$ 
Where $A_{1}$ and $A_{2}$ are the measured absorbances; $a_{1}, b_{1}, a_{2}, b_{2}$ and $b_{2}^{\prime}$ are constants found when developing the calibration curves; and $\mathrm{C}_{\text {periodate }}$ and $\mathrm{C}_{\text {iodate }}$ are the concentrations $(\mathrm{mg} / \mathrm{L})$ of each species. The absorbance of known concentrations of $\mathrm{IO}_{3}{ }^{-}$and $\mathrm{IO}_{4}{ }^{-}$were measured to develop the calibration curves (Eq. 3 and 4) with results presented in the Tables S2 and S3.

\subsubsection{Chloride species in AOS}

Species tested for chloride speciation included hypochlorite $\left(\mathrm{ClO}^{-}\right)$, chlorite $\left(\mathrm{ClO}_{2}{ }^{-}\right)$and chlorate $\left(\mathrm{ClO}_{3}{ }^{-}\right)$. As for the iodide species, these were chosen because they are predicted to be electrochemically generated in the reactor. Unfortunately, a similar experiment as the iodide species in the CLS was not completed for chloride species. The chloride species were determined using a similar method as for iodide using Equations 5 to 8 which indicate that the chloride species will react with excess iodide to form triiodide (Epstein and Kustin 1985; Mohammad et al. 2010; Narayana et al. 2005; Nowack and Von Gunten 1999).

$$
\mathrm{ClO}_{3}^{-}+6 \mathrm{I}^{-}+6 \mathrm{H}^{+} \leftrightarrow \mathrm{I}_{2}+\mathrm{Cl}^{-}+3 \mathrm{H}_{2} \mathrm{O}
$$

5

$$
\mathrm{ClO}_{2}^{-}+4 \mathrm{I}^{-}+4 \mathrm{H}^{+} \leftrightarrow \underset{2}{2 \mathrm{I}}+\mathrm{Cl}^{-}+2 \mathrm{H}_{2} \mathrm{O}
$$

6

$$
\mathrm{ClO}^{-}+2 \mathrm{I}^{-}+2 \mathrm{H}^{+} \leftrightarrow \underset{2}{1 \mathrm{I}}+\mathrm{Cl}^{-}+\mathrm{H}_{2} \mathrm{O}
$$

7

$$
\mathrm{I}_{2+} \mathrm{I}^{-} \leftrightarrow \mathrm{I}_{3}^{-}
$$

8

The reactions are $\mathrm{pH}$ dependent on the absorbance of the triiodide was measured at different wavelengths to ensure that there is no interference between the oxidative chloride species. The concentration of hypochlorite was determined at a pH of 9.7 and a wavelength of $291 \mathrm{~nm}$; hypochlorite and chlorite at pH 4 and $381 \mathrm{~nm}$; and all three species at pH 4 and $300 \mathrm{~nm}$ (Table S4, S5, and S6). Note that the $\mathrm{pH}$ and wavelength for hypochlorite and chlorite were chosen by determining their maximum absorbances, while for all species it was chosen where contributing absorbances for all three species can be measured as a maximum. The three equations used to determine the concentrations of each species in a mixture included:

$A_{1}=a_{1}+b_{1} C_{\text {hypochlorite }}(9)$

$A_{2}=a_{2}+b_{2} C_{\text {hypochlorite }}+b_{2}^{\prime} C_{\text {chlorite }}(10)$

$A_{3}=a_{3}+b_{3} C_{\text {hypochlorite }}+b_{3}^{\prime} C_{\text {chlorite }}+b_{3}{ }_{3} C_{\text {chlorate }}(11)$ 
Where $A_{1}, A_{2}$ and $A_{3}$ are measured absorbances; $a_{1}, b_{1}, a_{2}, b_{2}, b_{2}^{\prime}, b_{3}, b_{3}^{\prime}, b_{3}^{\prime}$ are constants found when developing the calibration curves; and $\mathrm{C}_{\text {hypochlorite }}$ and $\mathrm{C}_{\text {chlorite }}$ and $\mathrm{C}_{\text {chlorate }}$ are the concentrations $(\mathrm{mg} / \mathrm{L})$ of the each species. The absorbance of known concentrations of $\mathrm{ClO}^{-}, \mathrm{ClO}_{2}{ }^{-}$and $\mathrm{ClO}_{3}{ }^{-}$were measured to develop the calibration curves (Eq. 9-11) with results presented in the Tables S4, S5 and S6.

\subsection{Preparation of synthetic stormwater}

Table 2 shows the general recipe for the synthetic stormwater (SSW) matrix that was used for the AOS experimental testing. All chemicals used in the SSW experiments were purchased from Fisher Scientific (Thermo Fisher Scientific, MA, USA) and were of ACS grade purity where applicable. Synthetic stormwater was used as a representative alternative to real stormwater given it can be easily and reliably replicated in any laboratory, thus allowing for the potential for direct comparisons between results of various studies. In comparison, real stormwater samples taken as part of a parallel study by our research group showed wide-ranging stormwater compositions which would be expected to have differing AOS treatment optimization for each individual stormwater sample. Generally, there are many potential recipes for SSW in the literature that take this variability into consideration while also including differences due to location, time of year, and intensity of storm events. Ultimately, a SSW matrix was chosen based on literature that used a SSW to test urban stormwater treatment which has been used by a variety of researchers over the past 20 years (Davis, Shokouhian, Sharma, \& Minami, 1993; Hong, Seagren, \& Davis, 2006; Okochi \& McMartin, 2012). There were two sets of SSW experiments used to test the AOS treatment process train. Stormwater Experiment 1 focused on disinfection using the AOS given its potential usage for wastewaters, including stormwater, having bacterial contamination including $E$. coli. Stormwater Experiment 2 included the focus on $E$. coli while additionally investigated the decontamination capability of the AOS in a treatment train. Note that the AOS was designed and optimized for disinfection and this research only determined the preliminary decontamination potential. 
Table 2

Synthetic stormwater (SSW) recipes

(adapted from Davis et al. 2001; Hong, Seagren, and Davis 2006; Okochi and McMartin 2012). Note SSW Experiment 2 concentrations indicate ranges with exact value used presented in Table 5.

\begin{tabular}{|llll|}
\hline Component & Material & Concentration & SSW Experiment \\
\hline $\mathrm{NO}_{3}{ }^{-}$ & Sodium Nitrate & $2 \mathrm{mg} / \mathrm{L}$ & 1 \\
\hline Organic N & Glycine & 2 to $20 \mathrm{mg} / \mathrm{L}$ & 2 \\
\hline Phosphorus & Dibasic sodium phosphate & $0.6 \mathrm{mg} / \mathrm{L}$ & 1 \\
\hline Dissolved solids & Calcium chloride & $0.6 \mathrm{to} 1.8 \mathrm{mg} / \mathrm{L}$ & 2 \\
\hline Suspended solids & Bentonite & $120 \mathrm{mg} / \mathrm{L}$ & 1 \\
\hline E. coli & E.coli MC4100 & $120 \mathrm{to} 600 \mathrm{mg} / \mathrm{L}$ & 2 \\
\hline E. coli & Epower E. coli ATCC 51813 & $50 \mathrm{to} 300 \mathrm{CFU} / 100 \mathrm{~mL}$ & 2 \\
\hline Copper & Cupric Sulfate & $0.08 \mathrm{mg} / \mathrm{L}$ & 1 \\
\hline Lead & Lead Chloride & $0.08 \mathrm{mg} / \mathrm{L}$ & 1 \\
\hline Zinc & Zinc Chloride & $0.6 \mathrm{mg} / \mathrm{L}$ & 1 \\
\hline Influent salt & Potassium lodide & $10 \mathrm{ppm}$ & 1 \\
\hline & & $5 \mathrm{ppm}$ & 1 \\
\hline
\end{tabular}

For Stormwater Experiment 1, sodium nitrate, glycine, dibasic sodium phosphate, bentonite, cupric sulfate, lead chloride, zinc chloride, and potassium iodide at the corresponding concentrations in Table 2 were mixed into a total volume of $120 \mathrm{~L}$ of reverse osmosis (RO) water (Millipore Canada, ON, CA). In addition, the $E$. coli standard strain was inoculated overnight in a $400 \mathrm{~mL}$ Luria Bertani broth (LB) using a pre-streaked plate of the MC4100 strain. The culture was then spun in a centrifuge, resuspended in RO water, and added to the SSW prior to running the experiments. The Stormwater Experiment 1 experiments were completed as part of an internship by N.B. at the laboratory facilities of BioLargo Water Inc. in Edmonton, $A B$. 
For Stormwater Experiment 2, sodium nitrate, glycine, dibasic sodium phosphate, calcium chloride, and potassium iodide at the corresponding concentrations ranges shown in Table 2 (actual concentrations are included with experimental results in Table 5) were mixed into a total volume of $25 \mathrm{~L}$ of deionized (DI) water produced via a Millipore Direct-Q 8 UV system (Millipore Canada, ON, CA). The E. coli was prepared using the standard method given by the supplier (Microbiologics Inc., MN, USA) and added to the SSW prior to running the experiments. These experiments were performed in the Environmental Engineering laboratories at the University of Saskatchewan in Saskatoon, SK.

\subsection{Synthetic Stormwater treatment using the AOS}

The Stormwater Experiment 1 focused on testing the disinfection of $E$. coli in a laboratory setup that included a larger version of the AOS reactor with a 2" diameter and 12 chamber configuration (BioLargo Water Inc., Canada), a peristatic pump, and a DC power supply. The prepared SSW was pumped through the AOS in an upflow direction at a constant $1 \mathrm{~L} / \mathrm{min}$ flow rate and the AOS was connected to a DC power supply set at a constant $250 \mathrm{~mA}$ current. Samples to test the residual E. coli concentration were collected from the treated effluent every $30 \mathrm{~min}$ (including at time "0"). The samples were plated on LB agar (LBA) plates using a spiral plater, incubated at $35^{\circ} \mathrm{C}$ for $24 \mathrm{~h}$, and the colonies were counted. In addition, a sample from the "stock" SSW prior to treatment was collected and plated to determine the initial E. coli concentration. Note that experiments did not include any pre-treatment prior to the AOS for these runs.

The Stormwater Experiment 2 included a pre-treatment coagulation/flocculation step and the AOS treatment step. The coagulation/flocculation step would be expected to be used as an initial treatment process for the treatment of real stormwater to, at a minimum, decrease solids loading onto the AOS which could potentially lead to clogging of the reactor. Alum was chosen as the coagulant based on previous research (Harper \& Herr, 1987) and its historic use for water and wastewater treatment coagulation/flocculation. A jar test was conducted to determine the optimum concentration of alum for the SSW pre-treatment process. In addition, this apparatus was also used for the coagulation pretreatment step for these experiments. The ASTM standard of rapid mixing at 120 RPM for 1 min, slow mixing at 30 RPM for $20 \mathrm{~min}$, and settling for $30 \mathrm{~min}$ (ASTM International, 2013) was used for all experiments. The AOS laboratory setup consisted of influent pre-treated SSW, a variable speed peristaltic pump (VWR International, Edmonton, Canada) set at a constant pump rate $(100 \mathrm{~mL} / \mathrm{min})$, a DC power supply (Newark, Canada) set at a constant $40 \mathrm{~mA}$ current, and the 1" 6 chamber laboratory scale AOS reactor (Figure 1) which was used in the optimization iodide and chloride experiments. Samples were taken prior to treatment, after coagulation, and after the AOS.

Note that the current applied was different for each reactor from Stormwater Experiments 1 and 2 due the differing AOS sizes (12 vs. 6 chamber; 2" vs. 1") which impacted the current density within each AOS. The total current density within the AOS was approximately $12.7 \mathrm{~mA} / \mathrm{cm}^{2}$ for Stormwater Experiment 1 (1.15 $\mathrm{mA} / \mathrm{cm}^{2}$ per electrode) as compared to $8.2 \mathrm{~mA} / \mathrm{cm}^{2}$ for Stormwater Experiment $2\left(1.64 \mathrm{~mA} / \mathrm{cm}^{2}\right.$ per electrode). However, the resultant applied voltages were in the $\sim 7$ to $8 \mathrm{~V}$ range for both experimental conditions. 


\subsubsection{Synthetic stormwater quality parameter monitoring}

The total dissolved solids (TDS), electrical conductivity (EC), and pH were tested using typical laboratory meters. Chemical oxygen demand (COD) was measured using a spectrophotometer, vials, and digester (HACH USA, CO, USA). The total suspended solids (TSS) were measured using Standard Methods for quantifying solids in wastewaters ("2540 SOLIDS (2017)," 2018). A total organic carbon (TOC) analyzer and related standard method was used to measure the TOC concentrations. Lastly, E. coli was measured using m-ColiBlue24 Broth PourRite Ampules (Hach USA, Colorado USA).

\section{Results And Discussion 3.1 lodide Results}

The concentrations of iodate and periodate formed using 10,25, and $50 \mathrm{ppm} \mathrm{KI}$ concentrations at various voltages are shown in Figure 2 (Panels $A, B$, and $C$ ) as total oxidative iodide concentrations while the raw data and Figure 2 complementary information for the concentrations of each individual species are presented in Table S7 (10 ppm), S8 (25 ppm), and S9 (50 ppm). The resultant current that was applied to the reactor for each experimental condition is shown in Table 3.

Table 3

Measured current (A) applied to the AOS at constant voltage inputs for various experimental treatments of iodide $(\mathrm{KI})$, chloride $(\mathrm{NaCl})$, and no salt added.

\begin{tabular}{|llll|}
\hline & \multicolumn{3}{l|}{ Current (A) } \\
\hline Treatment & $\mathbf{6} \mathbf{~ V}$ & $\mathbf{1 2} \mathbf{~ V}$ & $\mathbf{2 4} \mathbf{~ V}$ \\
\hline 10 ppm KI & 0.01 & 0.02 & 0.07 \\
\hline $\mathbf{2 5}$ ppm KI & 0.02 & 0.05 & 0.10 \\
\hline $\mathbf{5 0}$ ppm KI & 0.01 & 0.05 & 0.10 \\
\hline Tap + 50 ppm KI & 0.08 & 0.22 & 0.65 \\
\hline $\mathbf{1 0}$ ppm NaCl & 0.01 & 0.04 & 0.15 \\
\hline $\mathbf{2 5}$ ppm NaCl & 0.01 & 0.05 & 0.20 \\
\hline $\mathbf{5 0}$ ppm NaCl & 0.02 & 0.07 & 0.25 \\
\hline No salt added & 0.02 & 0.07 & 0.31 \\
\hline
\end{tabular}


Overall, iodate was the dominant oxidative species at all KI concentrations and all applied voltages, typically having 5 to 10 times higher concentrations than periodate for all sampled anode and cathode ports. Interestingly, periodate started to form at the higher applied voltage of $24 \mathrm{~V}$ and $10 \mathrm{ppm} \mathrm{KI}$, and at the higher $\mathrm{KI}$ concentrations of $25 \mathrm{ppm}$ and $50 \mathrm{ppm}$ and voltage of $6 \mathrm{~V}$. It is indicative that higher concentrations/voltages could lead to the formation of highly and even very highly oxidized species and demanding more input energy (Figure S1; very highly oxidized species herein were not reported given their very short life-span and associated difficulties in measurement). This higher energy input resulted in much higher currents applied in the AOS (Table 3), which also increased with increasing salt concentrations, and generated excessive heat $\left(\sim 40-45^{\circ} \mathrm{C}\right.$; experiments were performed at room temperature $\sim 22^{\circ} \mathrm{C}$ ) that could potentially impact the integrity of the AOS. However, higher treatment temperatures may increase the effectiveness of treatment if the AOS is designed to handle these higher temperatures given faster reaction rates would likely result from the temperature increase. Creation of oxidative species increased with increasing voltages for all KI concentrations with $24 \mathrm{~V}$ showing the highest generation in all experiments (Figure 2). However, the excessive heat generation, coupled with the increased costs that would be expected for the higher voltage input, make the $24 \mathrm{~V}$ application unlikely for use in real wastewater treatment.

lodate was found in both the anodes and cathodes, while periodate was not found in both the anode and cathodes at $10 \mathrm{ppm} \mathrm{KI}$ and voltages less than $24 \mathrm{~V}$. The concentration of the oxidative species mostly increased after the anodes and decreased after the cathodes indicating that iodide was being oxidized at the anodes and reduced at the cathodes. This difference between samples between the anodes and cathodes was more prominent at higher voltages and $\mathrm{KI}$ concentrations given the higher reduction/oxidation potential at higher voltages and concentrations of salt in the reactor. In contrast, there are some contradictions. For example, the oxidative species concentrations reduced after A3 at 25 ppm KI and all voltages (Figure 2B) and increased after C1 at 50 ppm KI (Figure 2C). It should be noted that the sampling ports on the reactor are not perfectly aligned with anodes/cathodes and are closely spaced together, thus, complete reduction/oxidation between them would not be expected. This could be due to issues in the hand-packing process of the AOS which could be solved by using a commercial reactor design.

In general, iodide oxidative species that can be formed include hypoiodous acid $(\mathrm{HOI})$, iodite $\left(\mathrm{IO}_{2}^{-}\right)$iodate $\left(\mathrm{IO}_{3}^{-}\right)$and periodate $\left(\mathrm{IO}_{4}^{-}\right)$with iodate being the most commonly formed and stable species (Wang et al., 2018; Ye et al., 2012). The use of iodide is more desirable than other salts, such as chloride and bromide, because the hazardous oxidative iodide species formed are readily transformed back to nonhazardous iodide (Feng et al., 2017). However, hazardous iodinated disinfection by-products such as iodoforms can also be formed (Wang et al., 2018; Ye et al., 2012).

The percentage of total oxidative species generated based on the input KI concentration total are shown in Figure 3 (Panels A, B, and C). As would be expected, as voltage increased there was also an increase in the oxidative iodate and periodate species, particularly at the anodes, with $10 \mathrm{ppm}$ totals of $40-70 \%, 80$ $90 \%$, and approximately $100 \%$ for 6,12 and $24 \mathrm{~V}$ inputs, respectively. Following the same trend, $25 \mathrm{ppm}$ 
totals were $20-60 \%, 50-100 \%$ and $85-100 \%$ and 50 ppm totals were $15-30 \%, 70-90 \%$ and $80-100 \%$, respectively. Clearly, the lower the applied voltage, the lower the formation of oxidative species regardless of the initial KI concentration. Interestingly, there was a possibility that other oxidative species such as $\mathrm{HOI}$ and $\mathrm{IO}_{2}{ }^{-}$were being formed at lower voltages (Wang et al., 2018; Ye et al., 2012) but these were not determined in the current study. However, it is unlikely that $\mathrm{HOI}$ is formed since acidic conditions are needed for formation and it is an unstable species (Wang et al. 2018). Based on this analysis, the optimal combination of maximum oxidative species and voltage selection for use in the AOS for treatment purposes would be $10 \mathrm{ppm}$ and $12 \mathrm{~V}$. The $10 \mathrm{ppm}$ concentration had the highest percentage of iodate and periodate created, thus an increased dosage may be unnecessary for treatment purposes. The $12 \mathrm{~V}$ treatments were markedly higher than the $6 \mathrm{~V}$ treatments, while the $24 \mathrm{~V}$ treatment was only marginally better than the $12 \mathrm{~V}$ treatment overall. In addition, the added cost of applying $24 \mathrm{~V}$ versus $12 \mathrm{~V}$ and the potential negative impacts of the heat generation at $24 \mathrm{~V}$ make the $12 \mathrm{~V}$ option recommended.

The next experimental treatment considered tap water with $50 \mathrm{ppm} \mathrm{KI}$ treated in the AOS at 6, 12 and 24 $\mathrm{V}$. The concentrations of the oxidative periodate and iodate species for the tap water treatment are shown in Figure 4 in comparison to the 50 ppm KI DI water results shown previously, while the individual species raw data is included in Table S10. Interestingly, the tap water showed higher oxidative species concentrations for the $6 \mathrm{~V}$ and $12 \mathrm{~V}$ experiments versus the DI water results. In addition, the difference in concentration between the anodes and cathodes when tap water was used was greater than DI water. The increase in oxidative species may be due to the increased current (about 4 to 8 times higher) that was applied through the reactor at the same $\mathrm{KI}$ concentration and voltage applied for the tap water versus DI water treatments (Table 3). The increased current can be attributed to the higher number of ions present in tap water versus DI water. The increased current may have allowed the reactor to approach the threshold potential necessary for maximum production of oxidative species. Clearly, tap water results indicate that iodide species may be naturally found in the tap water which can be oxidized within the AOS. Alternatively, the tap water may have other oxidative species present, or created in the AOS, that could have enhanced production of the measured species, iodate and periodate. For example, chloride is known to be present in tap water created in the City of Saskatoon (City of Saskatoon, 2017) and is a common chemical added for protection of treated water before distribution. Given this result, chloride was assessed for its potential to create oxidative chloride species within the AOS in the next stage of experiments.

\subsection{Chloride Results}

The concentrations of chlorite and chlorate formed using 10,25, and $50 \mathrm{ppm} \mathrm{NaCl}$ concentrations at various voltages are shown in Figure 2 (Panels D, E, and F) as total oxidative chloride concentrations while concentrations of the raw data and Figure 2 complementary information for each of the individual species are presented in Table S11 (10 ppm), S12 (25 ppm), and S13 (50 ppm). As for the iodide results, the resultant current applied to the reactor for each experimental condition is shown in Table 3. 
Overall, chlorite was the dominant oxidative species at all $\mathrm{NaCl}$ concentrations and applied voltages to the AOS whereas chlorate was only found in some experiments when $6 \mathrm{~V}$ was applied to the reactor. As for iodide, the current applied to the AOS increased with increasing $\mathrm{NaCl}$ concentration and applied voltage (Table 3). Creation of the two measured oxidative species was at a maximum at $6 \mathrm{~V}$ for the 10 and $25 \mathrm{ppm} \mathrm{NaCl}$ treatments and decreased with increasing voltages (Figure 2). The $50 \mathrm{ppm} \mathrm{NaCl}$ treatment showed negligible concentrations of both chlorite and chlorate regardless of the input voltage. As compared to $\mathrm{KI}$ experiments, the trends for $\mathrm{NaCl}$ were unexpected and some results were conflicting. For example, the concentration of the oxidative species increased at the cathodes and decreased at the anodes with $6 \mathrm{~V}$ and $10 \mathrm{ppm} \mathrm{NaCl}$ treatment. However, they increased the anodes and decreased at the cathodes at all voltages for the $25 \mathrm{ppm} \mathrm{NaCl}$ treatment. Thus, more research would be needed to better assess the trends for $\mathrm{NaCl}$.

The percentage of total oxidative species generated based on the total input $\mathrm{NaCl}$ concentration are shown in Figure 3 (Panels $D, E$, and F). The measured oxidative species were only significantly formed for the $10 \mathrm{ppm} \mathrm{NaCl}$ treatment at $6 \mathrm{~V}$ with totals of $20-100 \%$. Oxidative species were formed for all voltages for the $25 \mathrm{ppm} \mathrm{NaCl}$ treatment, decreasing with input voltages with totals of $25-100 \%, 15-30 \%$ and $5-20 \%$ for 6,12 and $24 \mathrm{~V}$ respectively. There was a negligible concentration of chlorite and chlorate formed when $50 \mathrm{ppm} \mathrm{NaCl}$ was applied to the AOS as indicated previously. Generally, the lack of chlorite and chlorate may be due to the creation of other unmeasured oxidative species, such as perchlorate, being formed within the AOS. These species can be the result of higher currents generated in the reactor when increasing the applied voltage and/or increased the salt concentrations (Table 3).

Chloride is a potentially viable salt for production of oxidative species as it is commonly found in many wastewaters making addition unnecessary for treatment purposes. Chloride species that can be formed include chlorine gas $\left(\mathrm{Cl}_{2}\right)$, hypochlorous acid $(\mathrm{HClO})$, hypochlorite $\left(\mathrm{ClO}^{-}\right)$, chlorite $\left(\mathrm{ClO}_{2}{ }^{-}\right)$and chlorate $\left(\mathrm{ClO}_{3}{ }^{-}\right)$, with each species shown previously to be electrochemically generated (Bergmann et al., 2014; Oturan et al., 2015; Sirés et al., 2014). The HClO is the most powerful oxidant but is only formed in highly acidic conditions; it is also difficult to measure so was not included in the current species being assessed. The voltage applied to any electrochemical reactor system is important because if the anodic potential is too high, chlorate and perchlorate species can be formed. This scenario should be avoided as these species do not have any oxidation capacity and are known to be hazardous (Bergmann et al., 2014; Chaplin, 2014; Moreira et al., 2017; Radjenovic \& Sedlak, 2015; Sirés et al., 2014). Thus, determination of these species currently would be a little value as they are not valuable for wastewater treatment purposes. In addition, no hypochlorite was found in any of the samples, thus, it is not included in further discussion. Clearly, the higher the applied voltage and $\mathrm{NaCl}$ treatment concentration applied to the AOS, the lower the formation of chlorite and chlorate, and potentially other species such as perchlorate can be created. Interestingly, Bergmann et al. (2014) used boron doped diamond (BDD) electrodes and found that chlorate is steadily formed and if the electrolysis time is long enough, all the chloride is reacted to perchlorate. Potentially using lower input voltages would lead to a decrease in applied current, or lowering the $\mathrm{pH}$ of the influent water below 4 , which would both help to achieve lower oxidation states of chloride, 
such as hypochlorite, to be formed for safe and effective treatment (Cabeza et al. 2007; Juang et al. 2013). Currently, the comparison between iodide and chloride was done at three input voltages based on preliminary studies, thus lower voltage experiments were not considered.

Despite somewhat marginal result for $\mathrm{NaCl}$, the optimal combination of $\mathrm{NaCl}$ concentration and applied voltage to create the most chlorite within the AOS for treatment purposes would be $10 \mathrm{ppm}$ and $6 \mathrm{~V}$, respectively. Increasing the $\mathrm{NaCl}$ concentration and/or the applied voltage to the AOS led to decreases in the total concentrations and percentages of chlorite and chlorate formed while increases the risk of harmful higher oxidative species, such as perchlorate, being formed within the reactor and potentially discharged the outlet of the AOS into the environment.

\subsection{Comparing iodide and chloride}

Overall, the concentrations of oxidative species formed for each of the various iodide and chloride treatments can be compared in Figures 2 and 3. The biggest difference between the salts is that the concentration of iodide oxidative species increases with increasing voltage, whereas the chloride species decrease with increasing voltage. In addition, the percentage of measured oxidative species is generally higher for iodide treatments in most experiments. For both salts, when the concentration of salt and/or applied voltage was increased, the resultant current also increases (Table 3). In addition, the higher concentration of ions in the tap water vs. DI water also resulted in an increased measured current. Typical wastewaters can contain high concentrations of ions, therefore the applied current within the AOS will be expected to be high even at low input voltages. This will make it difficult to keep the current low for real wastewater treatment, thus, it is expected that only higher chloride oxidative species will be formed for this treatment. However, the concentration of iodide oxidative species increased with increasing current making the use of iodide with the AOS being the recommended combination for consideration for the assessment of treatment for real wastewaters.

\subsection{Synthetic stormwater preliminary results}

Following the assessment of the AOS for $\mathrm{KI}$ and $\mathrm{NaCl}$ concentrations, a synthetic stormwater (SSW) matrix was considered for treatment using the AOS. The optimum conditions for $\mathrm{KI}$ and $\mathrm{NaCl}$ were 10 ppm and $10 \mathrm{ppm}$, and $12 \mathrm{~V}$ and $6 \mathrm{~V}$, respectively. Based on these results, the initial Stormwater Experiment 1 used a $10 \mathrm{ppm} \mathrm{KI}$ solution for the AOS treatment process. Given the disinfection results (see below) were successful, a 5 ppm KI solution was used for the Stormwater Experiment 2 under the assumption that the added SSW chloride (Table 2) would work synergistically in the treatment of the SSW. Similarly, the optimum voltage would be expected to be in the range of 6 to $12 \mathrm{~V}$ based on the AOS optimization experiments. The SSW experiments controlled the current at $250 \mathrm{~mA}$ (Experiment 1) and 40 $\mathrm{mA}$ (Experiment 2) to maintain similar current densities in each reactor design. The measured voltage was in the 7 to $8 \mathrm{~V}$ range for all experiments. Results for $E$. coli reduction by the AOS are shown in Table 4 , while preliminary results for determination of a suite of physicochemical parameters and use of a flocculation treatment prior to the AOS are presented in Table 5. 
Table 4

Synthetic stormwater (SSW) results of Stormwater Experiment 1 for E. coli reduction using $10 \mathrm{ppm} \mathrm{KI}$ and $250 \mathrm{~mA}$ ( 7 to $8 \mathrm{~V}$ ).

\begin{tabular}{|llll|}
\hline Samples & $\mathbf{n}$ & $\begin{array}{l}\text { Average } \\
(\log \mathrm{CFU} / 100 \mathrm{~mL})\end{array}$ & $\begin{array}{l}\text { SD } \\
(\log \mathrm{CFU} / 100 \mathrm{~mL})\end{array}$ \\
\hline SSW Stock & $\mathbf{1 3}$ & 6.43 & 0.44 \\
& $\mathbf{1 3}$ & 3.68 & 4.08 \\
\hline AOS treated & $\mathbf{5 2}$ & 0.00 & 0.00 \\
\hline
\end{tabular}


Table 5

Preliminary synthetic stormwater (SSW) results for Stormwater Experiment 2 including all physicochemical parameters using $5 \mathrm{ppm} \mathrm{KI}$ and $40 \mathrm{~mA}(\sim 7$ to $8 \mathrm{~V})$. The modified SSW recipes were based on actual stormwater sample data collected as part of a parallel study (data not shown).

\begin{tabular}{|c|c|c|c|c|c|c|c|}
\hline Experiments & $\begin{array}{l}\mathrm{EC} \\
(\mu \mathrm{S} / \mathrm{cm})\end{array}$ & $\begin{array}{l}\text { TDS } \\
(\mathrm{mg} / \mathrm{L})\end{array}$ & $\mathrm{pH}$ & $\begin{array}{l}\mathrm{COD} \\
(\mathrm{mg} / \mathrm{L})\end{array}$ & $\begin{array}{l}\text { TOC } \\
\text { (mg/L) }\end{array}$ & $\begin{array}{l}\text { TSS } \\
(\mathrm{mg} / \mathrm{L})\end{array}$ & $\begin{array}{l}\text { E. coli } \\
\text { (CFU/100mL) }\end{array}$ \\
\hline \multicolumn{8}{|l|}{30 June } \\
\hline Initial & 1,409 & 700 & 7.12 & 83.1 & 18.8 & 160 & 200 \\
\hline $\begin{array}{l}60 \mathrm{ppm} \\
\text { Alum }\end{array}$ & 1,575 & 784 & 6.10 & 70.2 & 19.2 & 2.5 & 40 \\
\hline AOS & 1,373 & 680 & 6.15 & 68.0 & 16.8 & 6.5 & 6.5 \\
\hline \multicolumn{8}{|l|}{3 July } \\
\hline Initial & 2,010 & 1,010 & 6.88 & 329 & 32.0 & 110 & 310 \\
\hline $\begin{array}{l}60 \mathrm{ppm} \\
\text { Alum }\end{array}$ & 2,090 & 1,058 & 6.18 & 294 & 30.9 & 3.5 & 15 \\
\hline AOS & 1,825 & 913 & 5.76 & 228 & 9.60 & $<1.0$ & 7.5 \\
\hline \multicolumn{8}{|l|}{7 September } \\
\hline Initial & 511 & 248 & 6.90 & 39.5 & 7.15 & 110 & 42 \\
\hline $\begin{array}{l}60 \text { ppm } \\
\text { Alum }\end{array}$ & 577 & 280 & 6.94 & 32.5 & 2.73 & $<1.0$ & 17 \\
\hline AOS & 318 & 153 & 5.86 & 17.5 & 0.48 & $<1.0$ & $<1$ \\
\hline $\begin{array}{l}\text { Modified } \\
\text { SSW Recipe }\end{array}$ & $\begin{array}{l}\text { Sodium } \\
\text { Nitrate } \\
\text { (mg/L) }\end{array}$ & \multicolumn{2}{|c|}{$\begin{array}{l}\text { Glycine } \\
(\mathrm{mg} / \mathrm{L})\end{array}$} & \multicolumn{2}{|c|}{$\begin{array}{l}\text { Dibasic Sodium } \\
\text { Phosphate } \\
\text { (mg/L) }\end{array}$} & $\begin{array}{l}\text { Calcium } \\
\text { Chloride (mg/L) }\end{array}$ & $\begin{array}{l}\text { E. coli } \\
\text { (CFU/100mL) }\end{array}$ \\
\hline 30 June & 6 & \multicolumn{2}{|l|}{12} & 1.8 & \multicolumn{2}{|r|}{480} & 200 \\
\hline 3 July & 20 & \multicolumn{2}{|l|}{40} & 6 & \multicolumn{2}{|r|}{600} & 300 \\
\hline $\begin{array}{l}7 \\
\text { September }\end{array}$ & 2 & \multicolumn{2}{|l|}{6} & 0.6 & \multicolumn{2}{|r|}{120} & 50 \\
\hline
\end{tabular}

The Stormwater Experiment 1 included 13 sets of treatment runs (Table 4). The untreated stormwater had an average $E$. coli concentration of $\log 6.43(\mathrm{CFU} / 100 \mathrm{~mL}$ ) with a standard deviation of log $0.44 \mathrm{CFU} / 100$ $\mathrm{mL}$. The $\mathrm{T}=0 \mathrm{~min}$ sample had $\log 3.68$ (CFU/100 mL) with a high standard deviation of log $4.08 \mathrm{CFU} / 100$ $\mathrm{mL}$ due to about half of these samples have values below the detection limits. This variability could be attributed to operational variables including bacteria present in the tubing or the reactor prior to start-up and therefore $T=30$ min was considered the first timepoint to assess performance. At $T=30 \mathrm{~min}$ and later timepoints, no $E$. coli was detected in up to a total $120 \mathrm{~L}$ of SSW treated with the AOS. Thus, the AOS showed a consistent 6 log disinfection of E. coli for the SSW using 10 ppm KI and $250 \mathrm{~mA}$ applied current 
indicating that this technology is well-suited to disinfection and has the promise to be successful for use in real stormwater treatment processes. This high efficiency for disinfection by the AOS is not surprising, as previous studies have shown consistent disinfection of wastewaters using other eAOPs. For example, Rajab et al. (2015) used a boron doped diamond AAOP and generated chloride oxidative species to achieve 4-8 log inactivation of Pseudomonas aeruginosa. Similarly, Feng et al. (2018) used a dimensional stable anode (DSA) eAOP and chloride species to achieve a 3 log (or total in this case) disinfection of $E$. coli present in both synthetic stormwater and real stormwater samples. Additionally, Cano et al. (2012) used a conductive diamond AAOP for treating a wastewater and found a greater than 4 log disinfection of E. coli.

Following the disinfection success of the Stormwater Experiment 1, the Stormwater Experiment 2 was used to test the ability of the AOS to provide for both disinfection and decontamination including three preliminary treatment runs. For these experiments, the $\mathrm{KI}$ concentration was reduced to $5 \mathrm{ppm}$ in an effort to reduce the potential costs associated with addition of $\mathrm{KI}$ in the treatment process. In addition, results prior to these experiments suggested that higher $10 \mathrm{ppm} \mathrm{KI}$ concentration may not be necessary for treatment of more complex matrices such as the current SSW which have other salts already available for creation of oxidative species. The $E$. coli initial concentrations were also reduced in these experiments (Table 5) to better represent concentrations found in real stormwater samples collected by our research team as part of a parallel study (Table S15). In addition, the sodium nitrate, glycine, dibasic sodium phosphate, and calcium chloride concentrations added to the synthetic stormwater were varied to better represent different contaminant variations in these real stormwaters (Table 5). Overall, the EC and TDS concentrations remained unchanged through the treatment process train and followed the added concentrations of calcium chloride and sodium nitrate which would be expected to impact these parameters. Generally, the COD, TOC, and TSS all decreased through the coagulation/flocculation and AOS treatment process with the TSS showing the largest reduction due to the coagulation/flocculation process. The initial $E$. coli concentrations were also reduced during the coagulation/flocculation process to a range of 17 to $40 \mathrm{CFU} / 100 \mathrm{~mL}$, while the AOS reduced these further to the range of $<1$ to 7.5 $\mathrm{CFU} / 100 \mathrm{~mL}$.

Overall, the Stormwater Experiment 1 indicated that the AOS has a large capacity for disinfection of stormwater, or other wastewaters, having high initial E. coli concentrations. It would be expected that this capability would also be beneficial for reduction of other wastewater pathogens. The results for Stormwater Experiment 2 showed that the addition of the coagulation/flocculation step prior to the AOS provided for a large decrease in TSS and E. coli concentrations with the AOS process further 'polishing' the SSW for these two parameters. Additionally, it is important to note that the electrode surface structure might contribute to pollutant removal processes, however, previous study has shown that there is minimum adsorption relevant to electrode surface without iodine and/or electrical potential (Moustafa et al. 2021). Assessment of the AOS for treatment of real stormwater samples is currently underway in our research labs and will be presented in a future research article as they are beyond the scope of the current study. However, the results here for the SSW indicate that the treatment process train including coagulation/flocculation followed by the AOS shows promise for treatment of real stormwater samples. 


\section{Conclusions}

Real wastewaters and stormwaters are complex matrices containing many compounds, such as organic matter, that could be electrochemically oxidized, potentially into hazardous compounds including halogenated disinfection by-products. Given this complexity, it is important to determine the oxidative species formed within eAOPs, such as this unique AOS, to assess if they are potentially useful for wastewater treatment (such as iodate and chlorite) or potentially hazardous species (such as perchlorate). It is also useful to know the appropriate salt concentration and applied voltage for optimized creation of oxidative species in the AOS that could result in the most effective treatment when applied to real wastewaters. In this study, the concentrations of iodate and periodate formed from the potassium iodide addition and chlorite and chlorate formed from the sodium chloride addition were determined in the AOS reactor. Operating parameters analysed encompassed the impacts of different salt concentrations and input voltages on the production of these oxidative species. Overall, the results showed that the addition of salts to the stormwater can be useful to decrease the applied voltage needed for effective treatment, and the iodine-based AOS produce oxidative species with disinfection and decontamination capabilities indicating that it has the potential for effective stormwater treatment. The dominant oxidative species were found to be iodate with iodide addition and chlorite with chloride addition. For iodide, the optimal conditions for creation of oxidative species were found to be $10 \mathrm{ppm} \mathrm{KI}$ and $12 \mathrm{~V}$. Similarly, the $10 \mathrm{ppm} \mathrm{NaCl}$ and $6 \mathrm{~V}$ conditions were optimal for chloride. The AOS showed excellent disinfection of SSW E. coli using $10 \mathrm{ppm} \mathrm{KI}$ and a 2" 12 chamber reactor. The AOS also exhibited $E$. coli disinfection of SSW E. coli using $5 \mathrm{ppm} \mathrm{KI}$ and a 1" 6 chamber reactor. Additional studies testing stormwater treatment in treatment train and energy cost calculation will have to be done to further test the disinfection and decontamination capability of the AOS and evaluate its cost-effectiveness.

\section{Declarations}

\section{Acknowledgments}

The authors gratefully acknowledge the financial support provided through a NSERC Connect, Engage, and Engage Plus grants (to K.M). NRC-IRAP funded the Storm Water Pilot with BioLargo Water and provided financial and salary support. Finally, we would also like to recognize the financial support from BioLargo Water Inc. Canada and BioLargo Cooperate in Westminster CA.USA.

\section{Ethical Approval}

Not applicable

\section{Consent to Participate}

Not applicable

\section{Consent to Publish}


Not applicable

\section{Authors Contributions}

NB and RA performed all experiments at the University of Saskatchewan. LPF assisted with all experiments conducted at BioLargo Water Inc. Canada. NB, RA, LPF, and KNM were major contributors to the manuscript. All authors read and approved the final manuscript.

\section{Funding}

The authors gratefully acknowledge the financial support provided through a NSERC Connect, Engage (EGP 503902-16), and Engage Plus (EGP2 523101 - 18) grants (to KM). NRC-IRAP funded the Storm Water Pilot with BioLargo Water and provided financial and salary support. Finally, we would also like to recognize the financial support from BioLargo Water Inc. Canada and BioLargo Cooperate in Westminster CA.USA.

\section{Competing Interests}

The authors declare that they have no competing interests.

\section{Availability of data and materials}

Not applicable.

\section{References}

1. 2540 SOLIDS (2017). (2018). In Standard Methods For the Examination of Water and Wastewater. American Public Health Association.

2. Afkhami, A., Madrakian, T., \& Zarei, A. R. (2001). Spectrophotometric Determination of Periodate, lodate and Bromate Mixtures Based on Their Reaction with lodide. Analytical Sciences, 17(10), 1199-1202.

3. Ahmadi, M., Ramavandi, B., \& Sahebi, S. (2015). Efficient degradation of a biorecalcitrant pollutant from wastewater using a fluidized catalyst-bed reactor. Chemical Engineering Communications, 202(8), 1118-1129.

4. ASTM International. (2013). ASTM D2035-13. Standard Practice for Coagulation-Flocculation Jar Test of Water. The American, 11.01, 13-16.

5. Bergmann, M. E. H., Koparal, A. S., \& lourtchouk, T. (2014). Electrochemical Advanced oxidation processes, formation of halogenate and perhalogenate species: A critical review. Critical Reviews in Environmental Science and Technology, 44(4), 348-390.

6. Bilińska, L., Gmurek, M., \& Ledakowicz, S. (2016). Comparison between industrial and simulated textile wastewater treatment by AOPs-Biodegradability, toxicity and cost assessment. Chemical 
Engineering Journal, 306, 550-559.

7. Cabeza, A., Urtiaga, A. M., \& Ortiz, I. (2007). Electrochemical treatment of landfill leachates using a boron-doped diamond anode. Industrial and Engineering Chemistry Research, 46(5), 1439-1446.

8. Cañizares, P., Martínez, L., Paz, R., Sáez, C., Lobato, J., \& Rodrigo, M. A. (2006). Treatment of Fentonrefractory olive oil mill wastes by electrochemical oxidation with boron-doped diamond anodes. Journal of Chemical Technology and Biotechnology, 81(8), 1331-1337.

9. Cano, A., Cañizares, P., Barrera-Díaz, C., Sáez, C., \& Rodrigo, M. A. (2012). Use of conductive-diamond electrochemical-oxidation for the disinfection of several actual treated wastewaters. Chemical Engineering Journal, 211-212, 463-469.

10. Chan, P. Y., Gamal El-Din, M., \& Bolton, J. R. (2012). A solar-driven UV/Chlorine advanced oxidation process. Water Research, 46(17), 5672-5682.

11. Chaplin, B. P. (2014). Critical review of electrochemical advanced oxidation processes for water treatment applications. Environmental Sciences: Processes and Impacts, 16(6), 1182-1203.

12. Chauhan, R., Dinesh, G. K., Alawa, B., \& Chakma, S. (2021). A critical analysis of sono-hybrid advanced oxidation process of ferrioxalate system for degradation of recalcitrant pollutants. Chemosphere, 130324.

13. City of Saskatoon. (2017). Annual Water Quality Report.

14. Clark, S. E., \& Pitt, R. (2012). Targeting treatment technologies to address specific stormwater pollutants and numeric discharge limits. Water Research, 46(20), 6715-6730.

15. Davis, A., Shokouhian, M., Sharma, H., \& Minami, C. (1993). Laboratory study of biological retention for urban stormwater management. Water Environment Research, 73(1), 5-14.

16. Ding, J., Zhao, Q. L., Zhang, J., Jiang, J. Q., Li, W., Yu, H., ... Zhang, Y. S. (2017). Hybrid electrooxidation and adsorption process for the removal of ammonia in low concentration chloride wastewater. Environmental Science and Pollution Research, 24(6), 5098-5105.

17. Epstein, I. R., \& Kustin, K. (1985). Systematic design of chemical oscillators. Part 27. A mechanism for dynamical behavior in the oscillatory chlorite-iodide reaction. The Journal of Physical Chemistry, 89(11), 2275-2282.

18. Fajardo, A. S., Seca, H. F., Martins, R. C., Corceiro, V. N., Freitas, I. F., Quinta-Ferreira, M. E., \& QuintaFerreira, R. M. (2017). Electrochemical oxidation of phenolic wastewaters using a batch-stirred reactor with $\mathrm{NaCl}$ electrolyte and Ti/RuO2 anodes. Journal of Electroanalytical Chemistry, 785, 180189.

19. Feng, W., McCarthy, D. T., Henry, R., Zhang, X., Zhang, K., \& Deletic, A. (2018). Electrochemical oxidation for stormwater disinfection: How does real stormwater chemistry impact on pathogen removal and disinfection by-products level? Chemosphere, 213, 226-234.

20. Feng, W., McCarthy, D. T., Wang, Z., Zhang, X., \& Deletic, A. (2018). Stormwater disinfection using electrochemical oxidation: A feasibility investigation. Water Research, 140, 301-310. 
21. Feng, Yong, Lee, P. H., Wu, D., \& Shih, K. (2017). Rapid Selective Circumneutral Degradation of Phenolic Pollutants Using Peroxymonosulfate-lodide Metal-Free Oxidation: Role of lodine Atoms. Environmental Science and Technology, 51(4), 2312-2320.

22. Feng, Yujie, Yang, L., Liu, J., \& Logan, B. E. (2016). Electrochemical technologies for wastewater treatment and resource reclamation. Environmental Science: Water Research and Technology, 2(5), 800-831.

23. Fraser, A. N., Zhang, Y., Sakowski, E. G., \& Preheim, S. P. (2018). Dynamics and functional potential of stormwater microorganisms colonizing sand filters. Water (Switzerland), 10(8).

24. Ganiyu, S. O., Vieira dos Santos, E., Tossi de Araújo Costa, E. C., \& Martínez-Huitle, C. A. (2018). Electrochemical advanced oxidation processes (EAOPs) as alternative treatment techniques for carwash wastewater reclamation. Chemosphere, 211, 998-1006.

25. Harper, H. H., \& Herr, J. L. (1987). Chemical Coagulation of Stormwater Runoff: An Economical Alternative for Reducing Nonpoint Source Impacts.

26. Hong, E., Seagren, E. A., \& Davis, A. P. (2006). Sustainable Oil and Grease Removal from Synthetic Stormwater Runoff Using Bench-Scale Bioretention Studies. Water Environment Research, 78(2), 141-155.

27. Hussain, S. N., De las Heras, N., Asghar, H. M. A., Brown, N. W., \& Roberts, E. P. L. (2014). Disinfection of water by adsorption combined with electrochemical treatment. Water Research, 54, 170-178.

28. Jadhav, G. S., \& Ghangrekar, M. M. (2009). Performance of microbial fuel cell subjected to variation in $\mathrm{pH}$, temperature, external load and substrate concentration. Bioresource Technology, 100(2), 717723.

29. Juang, Y., Nurhayati, E., Huang, C., Pan, J. R., \& Huang, S. (2013). A hybrid electrochemical advanced oxidation/microfiltration system using $\mathrm{BDD} / \mathrm{Ti}$ anode for acid yellow 36 dye wastewater treatment. Separation and Purification Technology, 120, 289-295.

30. Lan, Y., Coetsier, C., Causserand, C., \& Serrano, K. G. (2017). On the role of salts for the treatment of wastewaters containing pharmaceuticals by electrochemical oxidation using a boron doped diamond anode. Electrochimica Acta, 231, 309-318.

31. Li, J., Feng, L., \& Jia, Z. (2006). Preparation of expanded graphite with $160 \mu \mathrm{m}$ mesh of fine flake graphite. Materials Letters, 60(6), 746-749.

32. Li, J., Liu, Q., \& Da, H. (2007). Preparation of sulfur-free exfoliated graphite at a low exfoliation temperature. Materials Letters, 61(8-9), 1832-1834.

33. Llanos, J., Cotillas, S., Cañizares, P., \& Rodrigo, M. A. (2014). Novel electrodialysis-electrochlorination integrated process for the reclamation of treated wastewaters. Separation and Purification Technology, 132, 362-369.

34. Mickova, I. (2015). Advanced Electrochemical Technologies in Wastewater Treatment Part I: Electrocoagulation. American Scientific Research Journal for Engineering, Technology, and Sciences (ASRJETS) ISSN, 14(2), 233-257. 
35. Mohammad, A. M., Awad, M. I., \& Ohsaka, T. (2010). Study of the autocatalytic chlorate-triiodide reaction in acidic and neutral media. Journal of Advanced Research, 1(3), 209-214.

36. Mohanty, S. K., Cantrell, K. B., Nelson, K. L., \& Boehm, A. B. (2014). Efficacy of biochar to remove Escherichia coli from stormwater under steady and intermittent flow. Water Research, 61, 288-296.

37. Moreira, F. C., Boaventura, R. A. R., Brillas, E., \& Vilar, V. J. P. (2015). Remediation of a winery wastewater combining aerobic biological oxidation and electrochemical advanced oxidation processes. Water Research, 75, 95-108.

38. Moreira, F. C., Boaventura, R. A. R., Brillas, E., \& Vilar, V. J. P. (2017). Electrochemical advanced oxidation processes: A review on their application to synthetic and real wastewaters. Applied Catalysis B: Environmental, 202, 217-261.

39. Moreira, F. C., Soler, J., Fonseca, A., Saraiva, I., Boaventura, R. A. R., Brillas, E., \& Vilar, V. J. P. (2015). Incorporation of electrochemical advanced oxidation processes in a multistage treatment system for sanitary landfill leachate. Water Research, 81, 375-387.

40. Moustafa, A., Evans, A., Hofstetter, S., Boutros, J., Pourrezaei, P., Zhang, C., Patterson-Fortin, L., Laing, C., Goertzen, C., Smith, R., Code, K., Chen, N., Blanchard, P., Bettman, N., Alam, R., McPhedran, K., Fallah, Z., Roberts, E., Gaultois, M. (2021). Operando Studies of lodine Species in an Advanced Oxidative Water Treatment Reactor. Environmental Science and Technology Water 1:2298-2304.

41. Narayana, B., Mathew, M., Vipin, K., Sreekumar, N. V, \& Cherian, T. (2005). An Easy Spectrophotometric Method for the Determination of Hypochlorite Using Thionin, 60(8), 798-801.

42. Nowack, B., \& Von Gunten, U. (1999). Determination of chlorate at low $\mu \mathrm{g} / \mathrm{l}$ levels by ionchromatography with postcolumn reaction. Journal of Chromatography A, 849(1), 209-215.

43. Okochi, N. C., \& McMartin, D. W. (2012). A laboratory study of the treatability of synthetic stormwater under varying conditions using electric arc furnace steel slag. Water (Switzerland), 4(2), 321-344.

44. Oturan, N., Van Hullebusch, E. D., Zhang, H., Mazeas, L., Budzinski, H., Le Menach, K., \& Oturan, M. A. (2015). Occurrence and Removal of Organic Micropollutants in Landfill Leachates Treated by Electrochemical Advanced Oxidation Processes. Environmental Science and Technology, 49(20), 12187-12196.

45. Radjenovic, J., \& Sedlak, D. L. (2015). Challenges and Opportunities for Electrochemical Processes as Next-Generation Technologies for the Treatment of Contaminated Water. Environmental Science and Technology, 49(19), 11292-11302.

46. Rajab, M., Heim, C., Letzel, T., Drewes, J. E., \& Helmreich, B. (2015). Electrochemical disinfection using boron-doped diamond electrode - The synergetic effects of in situ ozone and free chlorine generation. Chemosphere, 121, 47-53.

47. Sansalone, J. J., \& Kim, J. Y. (2008). Suspended particle destabilization in retained urban stormwater as a function of coagulant dosage and redox conditions. Water Research, 42(4-5), 909-922.

48. Seibert, D., Zorzo, C. F., Borba, F. H., de Souza, R. M., Quesada, H. B., Bergamasco, R., ... Inticher, J. J. (2020). Occurrence, statutory guideline values and removal of contaminants of emerging concern by Electrochemical Advanced Oxidation Processes: A review. Science of the Total Environment, 141527. 
49. Sirés, I., Brillas, E., Oturan, M. A., Rodrigo, M. A., \& Panizza, M. (2014). Electrochemical advanced oxidation processes: Today and tomorrow. A review. Environmental Science and Pollution Research, 21(14), 8336-8367.

50. Taylor, A., Flatt, A., Beutel, M., Wolff, M., Brownson, K., \& Stamets, P. (2015). Removal of Escherichia coli from synthetic stormwater using mycofiltration. Ecological Engineering, 78, 79-86.

51. Teh, C. Y., Budiman, P. M., Shak, K. P. Y., \& Wu, T. Y. (2016). Recent Advancement of CoagulationFlocculation and Its Application in Wastewater Treatment. Industrial and Engineering Chemistry Research, 55(16), 4363-4389.

52. Wang, X., Liu, Y., Huang, Z., Wang, L., Wang, Y., Li, Y., ... Ma, J. (2018). Rapid oxidation of iodide and hypoiodous acid with ferrate and no formation of iodoform and monoiodoacetic acid in the ferrate/l - /HA system. Water Research, 144, 592-602.

53. Ye, T., Xu, B., Lin, Y. L., Hu, C. Y., Xia, S. J., Lin, L., ... Gao, N. Y. (2012). Formation of iodinated disinfection by-products during oxidation of iodide-containing water with potassium permanganate. Journal of Hazardous Materials, 241-242, 348-354.

\section{Figures}




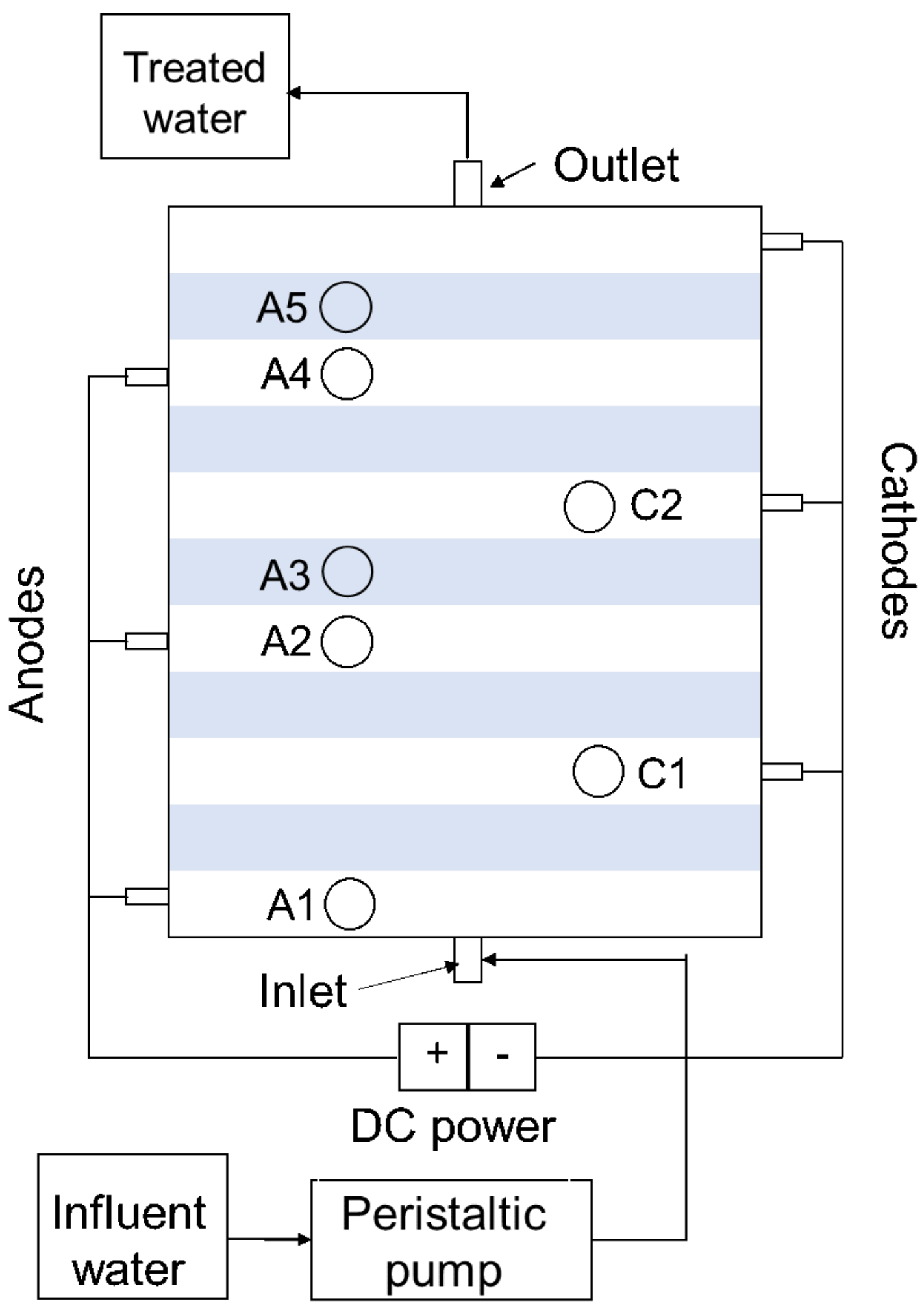

Figure 1

Schematic of the Advanced Oxidation System (AOS) reactor with alternating anodes and cathodes fed with DC power. The numbers A1-5 represent 'anode' sampling ports on the reactor and C1-2 (and C3 outlet) represent 'cathode' sampling ports. 


\section{Figure 2}

Concentrations of oxidative iodide (Panels A, B, C) and chloride (Panels D, E, F) species present in the $\mathrm{AOS}$ at various $\mathrm{KI}$ and $\mathrm{NaCl}$ doses.

\section{Figure 3}

Percentage of the total oxidative iodide (Panels A, B, C) and chloride (Panels D, E, F) species present in the $\mathrm{AOS}$ at various $\mathrm{KI}$ and $\mathrm{NaCl}$ doses. Note that more highly oxidized species were not determined in the current study. 

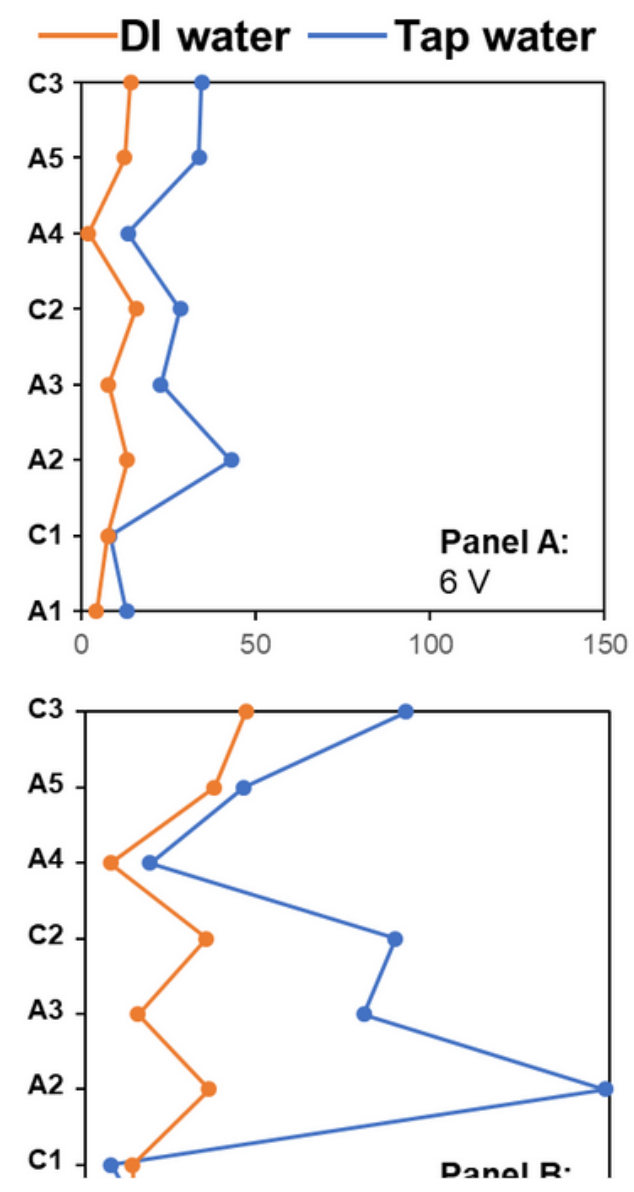

\section{Figure 4}

Total oxidative iodide species at $6 \mathrm{~V}$ (Panel A), $12 \mathrm{~V}$ (Panel B), and $24 \mathrm{~V}$ (Panel C) for distilled water (DI) and tap water samples including $50 \mathrm{ppm} \mathrm{KI}$ doses. 


\section{Supplementary Files}

This is a list of supplementary files associated with this preprint. Click to download.

- AOSOptimizationSIESPR.docx 